\title{
Ryanodine Receptor 2 Contributes to Impaired Protein Localization in Cyclic Nucleotide-Gated Channel Deficiency
}

\author{
Hongwei Ma, ${ }^{1}$ Fan Yang, ${ }^{1}$ Michael R. Butler, ${ }^{1}$ Jacob Rapp, ${ }^{1}$ Yun-Zheng Le, ${ }^{1,2,3,4}$ and ${ }^{\oplus}$ Xi-Qin Ding ${ }^{1}$
}

https://doi.org/10.1523/ENEURO.0119-19.2019

\begin{abstract}
${ }^{1}$ Department of Cell Biology, University of Oklahoma Health Sciences Center (OUHSC), Oklahoma City, Oklahoma 73104, ${ }^{2}$ Department of Medicine, University of Oklahoma Health Sciences Center (OUHSC), Oklahoma City, Oklahoma 73104, ${ }^{3}$ Department of Ophthalmology, University of Oklahoma Health Sciences Center (OUHSC), Oklahoma City, Oklahoma 73104, and ${ }^{4}$ Harold Hamm Diabetes Center, University of Oklahoma Health Sciences Center (OUHSC), Oklahoma City, Oklahoma 73104
\end{abstract}

\begin{abstract}
The photoreceptor cyclic nucleotide-gated (CNG) channel plays a pivotal role in phototransduction and cellular calcium homeostasis. Mutations in the cone photoreceptor CNG channel subunits CNGA3 and CNGB3 are associated with achromatopsia and cone dystrophies. CNG channel deficiency leads to endoplasmic reticulum (ER) stress-associated cone apoptosis, protein mislocalization, and ER calcium dysregulation. This work investigated the potential mechanisms of protein mislocalization associated with ER calcium dysregulation using $\mathrm{Cnga3}^{-/-}$mice lacking ER Ca ${ }^{2+}$ channel ryanodine receptor 2 (RyR2) specifically in cones. Deletion of Ryr2 improved outer segment (OS) localization of the cone proteins M-opsin, S-opsin, and cone phosphodiesterase subunit $\alpha^{\prime}$ (PDE6C) and decreased inner segment localization. One-month-old $\mathrm{Cnga3}^{-/-}$mice showed $\sim 30 \%$ of M-opsin, 55\% of S-opsin, and $50 \%$ of PDE6C localized to the OS. Cnga3 ${ }^{-/-}$mice with Ryr2 deletion at the same age showed almost $60 \%$ of M-opsin, $70 \%$ of S-opsin, and $70 \%$ of PDE6C localized to the OS. Deletion of Ryr2 nearly completely reversed elevations of the ER stress markers phospho-IRE $1 \alpha$ and phospho-elF $2 \alpha$ and suppressed cone apoptosis. Consistent with the improved cone protein localization and reduced ER stress/cone apoptosis, cone survival was improved by deletion of Ryr2. The number of cones was increased by $\sim 28 \%$ in $2-$ to 4-month-old $\mathrm{Cnga3}^{-/-}$mice with Ryr2 deletion compared with age-matched $\mathrm{Cnga3}^{-/-}$mice. This work demonstrates a role of RyR2/ER calcium dysregulation in protein mislocalization, ER stress, and cone death. The findings provide novel insights into the mechanisms of photoreceptor degeneration and support strategies targeting ER calcium regulation to manage retinal degeneration.
\end{abstract}

Key words: calcium channel; cone; endoplasmic reticulum; photoreceptor; retinal degeneration; ryanodine receptor

\section{Significance Statement}

The cyclic nucleotide-gated (CNG) channel plays a pivotal role in phototransduction and photoreceptor calcium homeostasis. Mutations in the cone CNG channel subunits are associated with achromatopsia and cone dystrophies. CNG channel deficiency leads to endoplasmic reticulum (ER) stress-associated cone apoptosis, protein mislocalization, and ER calcium dysregulation. This work demonstrates a role of $\mathrm{ER} \mathrm{Ca}^{2+}$ channel ryanodine receptor 2 and ER calcium dysregulation in protein mislocalization and subsequent ER stress and cone cell death. The findings provide novel insights into the mechanisms of photoreceptor degeneration. Altered calcium signaling and ER stress-associated cell death are common throughout retinal degenerative diseases. Thus, strategies targeting ER calcium regulation may help treat or slow photoreceptor degeneration. 


\section{Introduction}

The cone photoreceptor cyclic nucleotide-gated (CNG) channel plays a pivotal role in phototransduction. In darkness/dim light, the channel is kept open by the binding of cyclic guanosine monophosphate (cGMP), permitting the influx of $\mathrm{Ca}^{2+}$ and $\mathrm{Na}^{+}$necessary to maintain the dark current. Light induces hydrolysis of cGMP by photoreceptor phosphodiesterase 6 (PDE6), resulting in closure of the channel, hyperpolarization of the cell, and phototransduction (Bonigk et al., 1993; Kaupp and Seifert, 2002). Mutations in genes encoding the channel subunits CNGA3 and CNGB3 account for $\sim 80 \%$ of all cases of achromatopsia and are associated with progressive cone dystrophies (Kohl et al., 1998; Nishiguchi et al., 2005). These diseases are characterized by severely impaired daylight vision, lack of color discrimination, photophobia, and slow progressing degeneration of cones.

Mice lacking functional CNG channels mimic phenotypes in human patients, displaying impaired cone function and progressive cone degeneration (Biel et al., 1999; Ding et al., 2009). Mechanistic studies show that cone death in CNG channel-deficient mice involves endoplasmic reticulum (ER) stress-associated apoptosis (Thapa et al., 2012; Ma et al., 2013) and impaired protein localization. These mice show reduced opsin localization to the cone outer segment (OS) and increased opsin localization to the inner segment (IS) and other photoreceptor regions (Michalakis et al., 2005; Xu et al., 2011). Gene supplementation of the channel subunits resumed cone opsin OS localization, light response, and photoreceptor survival (Michalakis et al., 2010; Carvalho et al., 2011). Phototransduction proteins are synthesized/processed in the IS where ER is located and translocated to the OS where they function. Aberrant protein trafficking and localization has been associated with photoreceptor degeneration (Bales and Gross, 2016; Agrawal et al., 2017).

The CNG channel is essential for cellular calcium homeostasis (Hackos and Korenbrot, 1999; Krizaj and Copenhagen, 2002). Measurements of intracellular $\mathrm{Ca}^{2+}$ levels showed reduced cytoplasmic $\mathrm{Ca}^{2+}$ in cones of CNG channel-deficient mice (Butler et al., 2017). The cellular calcium perturbation was also supported by the remarkable elevation of cellular cGMP levels in these mice

Received March 27, 2019; accepted May 21, 2019; First published June 10, 2019.

The authors declare no competing financial interests.

Author contributions: H.M., M.R.B., Y.Z.-L., and X.-Q.D. designed research; H.M., F.Y., M.R.B., and J.R. performed research; H.M., F.Y., M.R.B., and J.R. analyzed data; H.M. and X.-Q.D. wrote the paper.

This work was supported by grants from the National Eye Institute (P30EY021725 and R01EY027754), the Oklahoma Center for the Advancement of Science and Technology. We thank Drs. Martin Biel, Anand Swaroop, and Muna Naash for providing $\mathrm{Cnga}^{-/-}$mouse line, $\mathrm{Nrl}^{-/-}$mouse line, and anti-S-opsin antibody; and the Imaging Core Facility and the Histology Core Facility of the Department of Cell Biology at OUHSC for technical assistance.

Correspondence should be addressed to Xi-Qin Ding at xi-qin-ding@ ouhsc.edu.

https://doi.org/10.1523/ENEURO.0119-19.2019

Copyright @ 2019 Ma et al.

This is an open-access article distributed under the terms of the Creative Commons Attribution 4.0 International license, which permits unrestricted use, distribution and reproduction in any medium provided that the original work is properly attributed.
(Xu et al., 2013), because cytosolic $\mathrm{Ca}^{2+}$ level negatively regulates biosynthesis of cGMP (Olshevskaya et al., 2002; Baehr and Palczewski, 2009). The $\mathrm{Ca}^{2+}$ measurements also showed altered cellular $\mathrm{Ca}^{2+}$ dynamics following ER store depletion (Butler et al., 2017). ER calcium homeostasis is primarily regulated by the two $\mathrm{ER} \mathrm{Ca}^{2+}$ channels, the ryanodine receptor (RyR) and inositol-1,4,5trisphosphate receptor (IP3R), for $\mathrm{Ca}^{2+}$ efflux out of the ER into the cytosol, and the sarco/endoplasmic reticulum $\mathrm{Ca}^{2+}$-ATPase, for $\mathrm{Ca}^{2+}$ influx into the ER. ER $\mathrm{Ca}^{2+}$ channels are highly regulated by cytosolic $\mathrm{Ca}^{2+}$ levels; their activity is increased when cytosolic $\mathrm{Ca}^{2+}$ level is low. In photoreceptors these channels are on the ER within the IS/perikaryon regions and regulate induction of phototransduction and tonic release of the photoreceptor neurotransmitter glutamate (Krizaj and Copenhagen, 2002; Krizaj, 2012). Photoreceptors express all three isoforms of RyR; RyR1, RyR2, and RyR3. RyR2 is the predominant form (Shoshan-Barmatz et al., 2007; Butler et al., 2017) and is distributed mainly in the IS of the photoreceptors and outer nuclear layer (Krizaj et al., 2003; Huang et al., 2011; Butler et al., 2017). Consistent with observed cytosolic calcium perturbation, CNG channel- deficient retinas show potential ER calcium dysregulation and impaired protein processing, manifested as elevated expression/ activity of RyR and IP3R (Thapa et al., 2012; Butler et al., 2017) and elevated activity of ER stress/ER-associated protein degradation markers (Ma et al., 2015). Moreover, treatment with $\mathrm{ER} \mathrm{Ca}^{2+}$ channel inhibitors reduced ER stress and cone death in these mice (Butler et al., 2017). This work investigated the effects of Ryr2 deletion on cone protein localization and ER stress. The OS localization of cone opsins and PDE6C was significantly increased in $\mathrm{Cnga3}^{-/-}$mice lacking Ryr2 and IS localization was significantly decreased, which were accompanied with reduced ER stress/cone death and improved cone survival. Our findings support the view that RyR2 function/ER calcium deficiency contributes to protein mislocalization and ER stress in CNG channel deficiency.

\section{Materials and Methods}

\section{Mice, antibodies, and other reagents}

The Cnga3 $^{-/-}$(Biel et al., 1999), Hrgp-cre [transgenic mice expressing Cre recombinase directed by the human $\mathrm{red} / \mathrm{green}$ pigment (HRGP) gene promoter; Le et al., 2004], and $\mathrm{Nrl}^{-1-}$ (Mears et al., 2001) mouse lines were generated as described previously. The Ryr2 $2^{\text {flox/flox }}$ (Bround et al., 2012) and wild-type (C57BL/6J) lines were obtained from The Jackson Laboratory (Ryr2 flox/flox, JAX stock \#026628; C57BL/6J, JAX stock \#000664). The



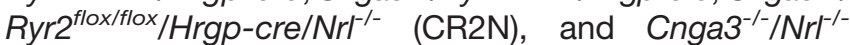
lines were generated by cross-breeding. All mice were housed under cyclic, $12 \mathrm{~h}$ light/dark conditions, with $\sim 7$ foot candles of illumination during the light cycle. Animal maintenance and experiments were approved by the local Institutional Animal Care and Use Committee (OUHSC) and conformed to the guidelines on the care and use of animals accepted by the Society for Neuroscience and the Association for Research in Vision and Ophthalmology 


\begin{tabular}{|c|c|c|c|}
\hline Antibody & Provider & Catalog no. & $\begin{array}{c}\text { Dilutions used in } \\
\text { immunoblotting (IB) or } \\
\text { immunofluorescence } \\
\text { labeling (IF) }\end{array}$ \\
\hline S-opsin & $\begin{array}{l}\text { Dr. Muna Naash from the } \\
\text { University of Houston }\end{array}$ & & $1: 200$ (IF) \\
\hline PDE6C & Abgent & ap9728c & $1: 200$ (IF) \\
\hline Biotinylated PNA & Vector Laboratories & B-1075 & $1: 200$ (IF) \\
\hline Phospho-elF2 $\alpha$ & Cell Signaling Technology, Beverly, MA & 3398 & $1: 500$ (IB) \\
\hline Phospho-IRE1a & Abcam, Inc., Cambridge, MA & $a b-48187$ & $1: 500$ (IB) \\
\hline$\beta$-actin & Abcam, Inc., Cambridge, MA & $a b-6276$ & $1: 2000$ (IB) \\
\hline
\end{tabular}

(Rockville, MD). Mice of either sex were used in the experiments.

Primary antibody information is listed in Table 1. Horseradish peroxidase-conjugated anti-rabbit secondary antibody was obtained from Kirkegaard \& Perry Laboratories, fluorescent-conjugated goat anti-rabbit antibody was purchased from Invitrogen (A21428), Streptavidin-Cy3 was purchased from Sigma-Aldrich (S6402), and DAPI was purchased from Sigma-Aldrich (D9542). Other reagents were obtained from Sigma-Aldrich, Bio-Rad, Invitrogen, Abcam, and Tocris Biosciences.

\section{Eye preparation, immunofluorescence labeling, and confocal microscopy}

Retinal whole mounts or cross sections were prepared for immunofluorescence labeling, as described previously (Ma et al., 2014). For retinal whole-mount preparations, eyes were enucleated, marked at the superior pole with a green dye, and fixed in 4\% paraformaldehyde (Polysciences) for $30 \mathrm{~min}$ at room temperature, followed by removal of the cornea and lens. The eyes were then fixed in $4 \%$ paraformaldehyde in PBS for 4-6 $\mathrm{h}$ at room temperature, and retinas were isolated and the superior portion was marked for orientation with a small cut. For retinal cross-sections, mouse eyes were enucleated (the superior portion of the cornea was marked with green dye before enucleation) and fixed in Prefer (Anatech) for 25-30 $\mathrm{min}$ at room temperature. Paraffin sections $(5 \mu \mathrm{m}$ thickness) passing vertically through the retina (along the vertical meridian passing through the optic nerve head) were prepared using a Leica microtome (Leica Biosystems).

Immunofluorescence labeling was performed as described previously (Ma et al., 2014). Briefly, retinal whole mounts or sections were blocked with Hanks' balanced salt solution containing $5 \% \mathrm{BSA}$ and $0.5 \%$ Triton X-100 for $1 \mathrm{~h}$ at room temperature or overnight at $4^{\circ} \mathrm{C}$. Prior to blocking, antigen retrieval was performed in $10 \mathrm{mM}$ sodium citrate buffer, $\mathrm{pH} 6.0$, in a $70^{\circ} \mathrm{C}$ water bath. Primaryantibody incubation was performed for $2 \mathrm{~h}$ at room temperature or overnight at $4^{\circ} \mathrm{C}$ (for antibody information, see Table 1). Slides were mounted and coverslipped after fluorescence-conjugated secondary-antibody incubation and wash steps. Immunofluorescence labeling was then imaged using an Olympus FV1000 confocal laserscanning microscope and FluoView imaging software
(Olympus). For evaluations of cone OS protein cellular localization, confocal images of 10 layers were stacked with the Z-stack function in the ImageJ software (https:// imagej.nih.gov/ij/) to obtain a maximal immunofluorescence density. Fluorescence density levels of the immunolabeling in the OS, IS, outer nuclear layer (ONL), and outer plexiform layer (OPL) were measured, and the density levels at each region relative to the total fluorescence density were calculated and averaged from at least three sections per eye from at least four animals per condition.

\section{Scotopic and photopic electroretinography recordings}

Full-field electroretinography (ERG) recordings were conducted as described previously ( $\mathrm{Xu}$ et al., 2011). Briefly, after overnight dark adaptation, mice were anesthetized by intraperitoneal injection of $85 \mathrm{mg} / \mathrm{kg}$ ketamine and $14 \mathrm{mg} / \mathrm{kg}$ xylazine. ERGs were recorded using an Espion visual electrophysiology system with a Ganzfeld ColorDome system (Diagnosys). Potentials were recorded using a gold-wire electrode to contact the corneal surface through a layer of $2.5 \%$ hypromellose (Gonak, Akorn). For assessment of scotopic responses, a stimulus intensity of $2.20 \mathrm{log} \mathrm{cd} \cdot \mathrm{s} \mathrm{m}^{-2}$ was presented to dark-adapted dilated mouse eyes. To evaluate photopic responses, mice were adapted to a $1.48 \mathrm{log} \mathrm{cd} \cdot \mathrm{s} \mathrm{m}^{-2}$ light for $5 \mathrm{~min}$, and then a light intensity of $1.89 \mathrm{log} \mathrm{cd} \cdot \mathrm{s} \mathrm{m}^{-2}$ was given. Responses were differentially amplified, averaged, and analyzed using Espion 100 software (Diagnosys).

\section{TUNEL assay}

Terminal deoxynucleotidyl transferase dUTP nick-end labeling (TUNEL) was performed to analyze photoreceptor apoptotic death as described previously (Ma et al., 2015), using paraffin- embedded retinal sections and an in situ cell death fluorescein detection kit (Roche Applied Science, 11684795910). Immunofluorescence labeling was imaged using an Olympus FV1000 confocal laserscanning microscope, and TUNEL-positive cells in the outer nuclear layer passing through the optic nerve were counted and averaged from at least three sections per eye from at least five animals per condition. 


\section{Retinal protein preparation, SDS-PAGE, and Western blot analysis}

Retinal protein preparation, SDS-PAGE, and Western blot analysis were performed as previously (Ma et al., 2015). Briefly, retinas were homogenized in homogenization buffer $\mathrm{A}$ (0.32 M sucrose, $20 \mathrm{mM}$ HEPES, pH 7.4, and $3 \mathrm{~mm}$ EDTA containing protease and phosphatase inhibitors; Roche Applied Science, catalog \#04693159001 and \#04906837001, respectively), and homogenates were centrifuged at $3000 \mathrm{rpm}$ for $10 \mathrm{~min}$ at $4^{\circ} \mathrm{C}$. The resulting supernatant was then centrifuged at $13,000 \mathrm{rpm}$ for 35 min at $4^{\circ} \mathrm{C}$ to separate cytosolic (supernatant) and membrane (pellet) fractions. The resulting membrane pellet was resuspended in homogenization buffer $B(0.32 \mathrm{M}$ sucrose, $20 \mathrm{~mm}$ HEPES, pH 7.4, 3 mM EDTA, and 0.1\% Triton $X-100$ containing protease and phosphatase inhibitors, as previously described), sonicated twice for $15 \mathrm{~s}$ on ice at a medium speed using an XL2000 Ultrasonic Cell Disruptor (Misonix), with a 30 s recovery between disruptions, and incubated for $1 \mathrm{~h}$ at $4^{\circ} \mathrm{C}$ with gentle agitation. After incubation, the homogenate was centrifuged at $13,000 \mathrm{rpm}$ for $35 \mathrm{~min}$ at $4^{\circ} \mathrm{C}$, and the resulting supernatant was used as the membrane fraction. All protein concentrations were determined by a protein-assay kit from Bio-Rad Laboratories. Retinal protein samples $(20 \mu \mathrm{g}$ protein per sample) were then subjected to SDS-PAGE and transferred to PVDF membranes, which were subsequently blocked in $5 \%$ bovine serum albumin (BSA) for 1 $\mathrm{h}$ at room temperature. Immunoblots were incubated with primary antibody overnight at $4^{\circ} \mathrm{C}$. After washing in Trisbuffered saline with $0.1 \%$ Tween 20 , immunoblots were incubated with horseradish peroxidase-conjugated secondary antibody $(1: 20,000)$ for $1 \mathrm{~h}$ at room temperature. SuperSignal West Dura Extended Duration chemiluminescent substrate (ThermoFisher Scientific, catalog \#34076) was used to detect binding of the primary antibodies to their cognate antigens. A Li-Cor Odyssey CLx Imager and $\mathrm{Li}$-Cor software (Li-Cor Biosciences) were used for detection and densitometric analysis.

\section{Statistical analysis}

One-way ANOVA and unpaired Student's $t$ test were used to evaluate significant differences between multiple groups and two groups, respectively. Statistical analyses and graph generation were performed using GraphPad Prism software (GraphPad Software) for Windows.

\section{Results}

\section{Deletion of Ryr2 increased OS localization of cone opsins in $\mathrm{Cnga3}^{-/-}$mice}

Retinal cross-sections of $\mathrm{Cnga3}^{-/-}$mice show decreased levels of opsin localized to the cone OS and increased opsin levels in the cone IS, ONLs, and OPLs (Michalakis et al., 2005, 2010; Carvalho et al., 2011; Komáromy et al., 2011; Xu et al., 2011). In this study, we examined cone opsin localization in $\mathrm{Cnga}^{-1-}$ mice lacking Ryr2 to determine the contribution of RyR2. Cnga3 ${ }^{-/-}$, $\mathrm{Cnga3}^{-/ /} / \mathrm{Ryr}^{\text {flox/flox}} / \mathrm{Hrgp}$-cre, Ryr2 $2^{\text {flox/flox}} / \mathrm{Hrgp}$-cre, and wild-type mice at postnatal day (P)30 were analyzed for $\mathrm{M}$-opsin and S-opsin cellular localization by immunofluo- rescence labeling on retinal cross sections. The data from this study are presented in Figure 1. Deletion of Ryr2 significantly increased $\mathrm{M}$-opsin localization to the cone OS in $\mathrm{Cnga3}^{-/-}$mice and decreased its localization to the IS. The OS immunofluorescence density level of M-opsin labeling was $\sim 30 \%$ of the total immunofluorescence level in the ventral retina of $\mathrm{Cnga3}^{-/-}$mice, and it was $\sim 60 \%$ of the total level in $\mathrm{Cnga3}^{-/-} / \mathrm{Ryr}^{\text {flox/flox}} / \mathrm{Hrgp}$-cre mice (Fig. $1 A, B)$. Similar improvement was observed in the dorsal region. The IS immunofluorescence density level was $\sim 30 \%$ of the total level in the ventral retina of $\mathrm{Cnga3}^{-/-}$ mice, and it was $\sim 15 \%$ of the total level in $\mathrm{Cnga3}^{-/-}$ Ryr2 $2^{\text {flox/flox}} / \mathrm{Hrgp}$-cre mice (Fig. $1 A, B$ ). Similar observation was obtained in the dorsal region.

The significantly reduced immunofluorescence level of $\mathrm{M}$-opsin labeling was also observed in the ONL and OPL regions. Similar to findings with $\mathrm{M}$-opsin cellular localization, deletion of Ryr2 significantly increased S-opsin localization to the OS in $\mathrm{Cnga}^{-/-}$mice and decreased its localization to the IS. The OS immunofluorescence density level of S-opsin labeling was $\sim 55 \%$ of the total level in the ventral retina of $\mathrm{Cnga3}^{-1-}$ mice, and it was $\sim 70 \%$ of the total level in $\mathrm{Cnga3}^{-/-} / \mathrm{Ryr}^{\text {flox/flox }} / \mathrm{Hrgp}$-cre mice (Fig. $1 C, D)$. The IS immunofluorescence density level was $\sim 23 \%$ of the total level in the ventral retina of $\mathrm{Cnga3}^{-/-}$ mice, and it was $\sim 15 \%$ of the total level in $\mathrm{Cnga3}^{-/-1}$ Ryr2 $^{\text {flox/flox }} / \mathrm{Hrgp}$-cre mice (Fig. 1C,D). The significantly reduced immunofluorescence level of S-opsin labeling was also observed in the ONL and OPL regions. In wildtype and Ryr $2^{\text {flox/flox } / H r g p-c r e ~ m i c e, ~ M-o p s i n ~ a n d ~ S-o p s i n ~}$ localized to the OS. There was no significant difference in opsin distribution between wild-type and Ryr2 flox/flox/ Hrgp-cre mice (Fig. 1).

\section{Deletion of Ryr2 improved OS localization of PDE6C in $\mathrm{Cnga3}^{-/-}$mice}

We also examined cellular localization of the $\alpha^{\prime}$ subunit of PDE6 complex, PDE6C, in Cnga3 ${ }^{-/-}$mice lacking Ryr2. Cnga3 $^{-/ /} /$Ryr2 $^{\text {flox/flox }} / \mathrm{Hrgp}$-cre, Cnga3 ${ }^{-/-}$, Ryr2 $2^{\text {flox/flox } / \mathrm{Hrgp}-}$ cre, and wild-type mice at P30 were analyzed for PDE6C cellular localization by immunofluorescence labeling on retinal cross sections. The data from this study are presented in Figure 2. In wild-type and Ryr2 ${ }^{\text {flox/flox }} / \mathrm{Hrgp}$-cre mice, PDE6C mainly localized to the OS. There was no detectable difference in PDE6C distribution between wild-

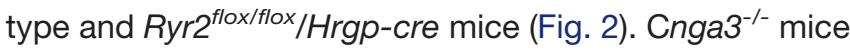
showed apparent PDE6C mislocalization to the IS. Deletion of Ryr2 significantly improved PDE6C localization to the OS and decreased its localization to the IS. The OS immunofluorescence density level of PDE6C labeling was $\sim 50 \%$ of the total immunofluorescence level in the ventral retina of $\mathrm{Cnga3}^{-/-}$mice, and it was $\sim 70 \%$ of the total level

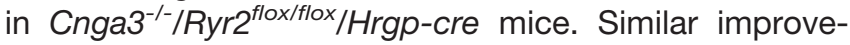
ment was observed in the dorsal region (Fig. 2). The IS immunofluorescence density level was $\sim 30 \%$ the total level in the ventral retina of $\mathrm{Cnga3}^{-/-}$mice, and it was $\sim 18 \%$ of the total level in $\mathrm{Cnga3}^{-/} / \mathrm{Ryr}^{\text {flox/flox}} / \mathrm{Hrgp}$-cre mice. Similar observation was obtained in the dorsal region (Fig. 2). 

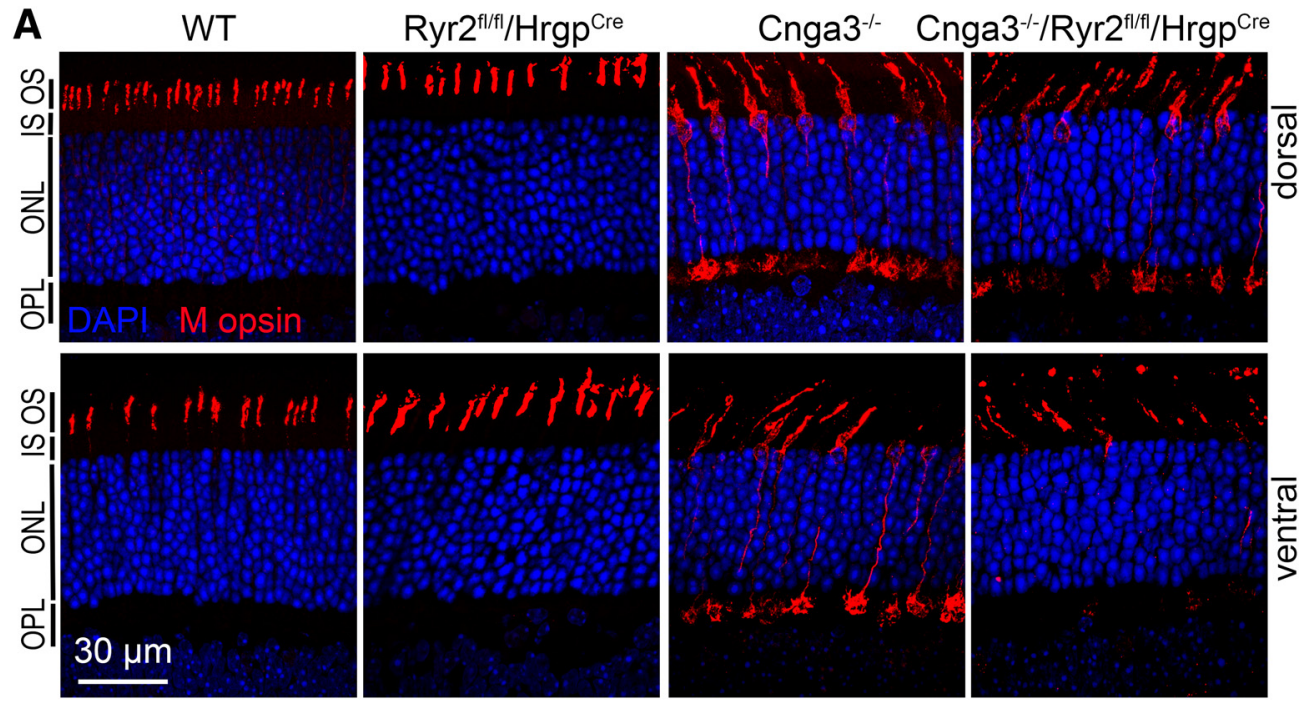

B
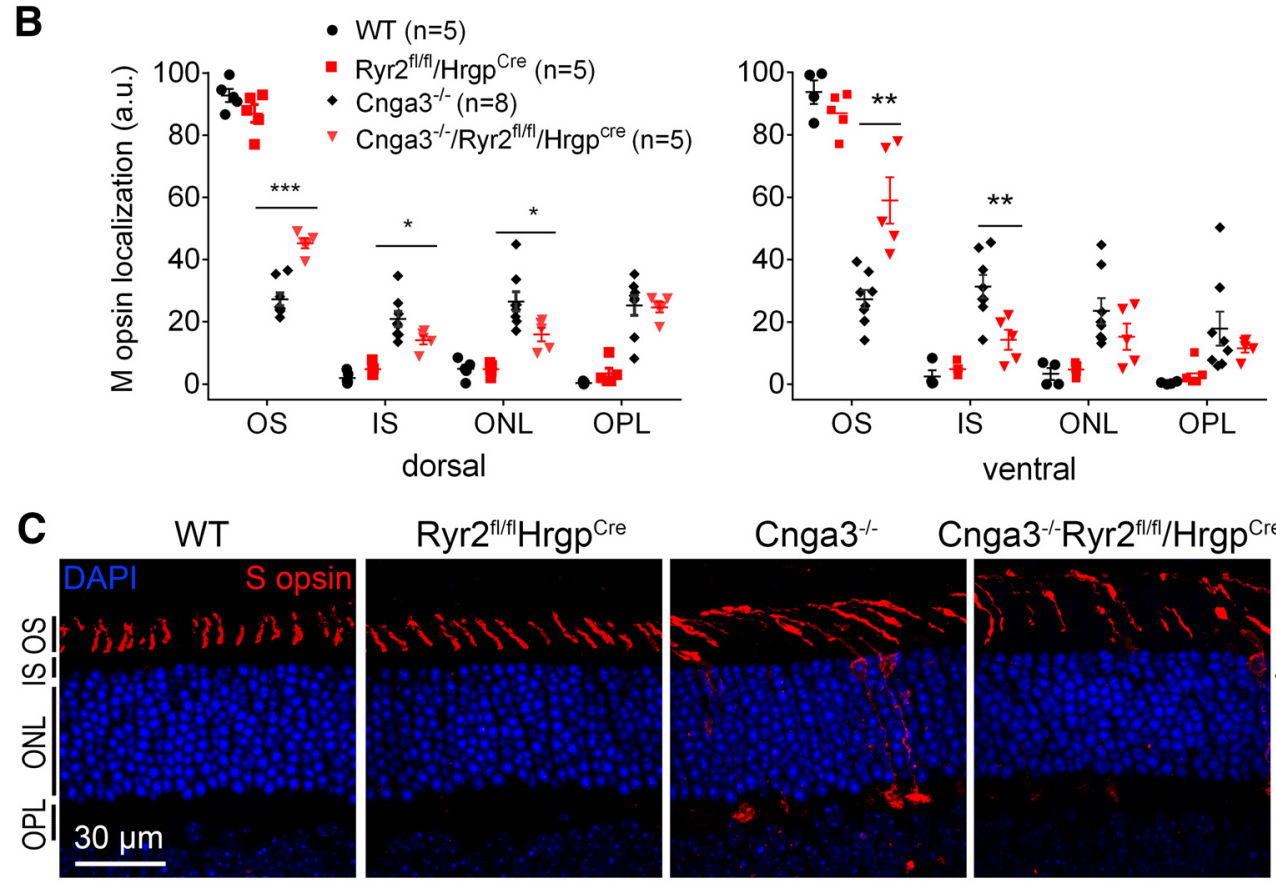

Cnga3 $^{-/-} \quad$ Cnga3 $^{-/-}$Ryr2 ${ }^{\text {fl/fil/Hrgp }}{ }^{\text {Cre }}$
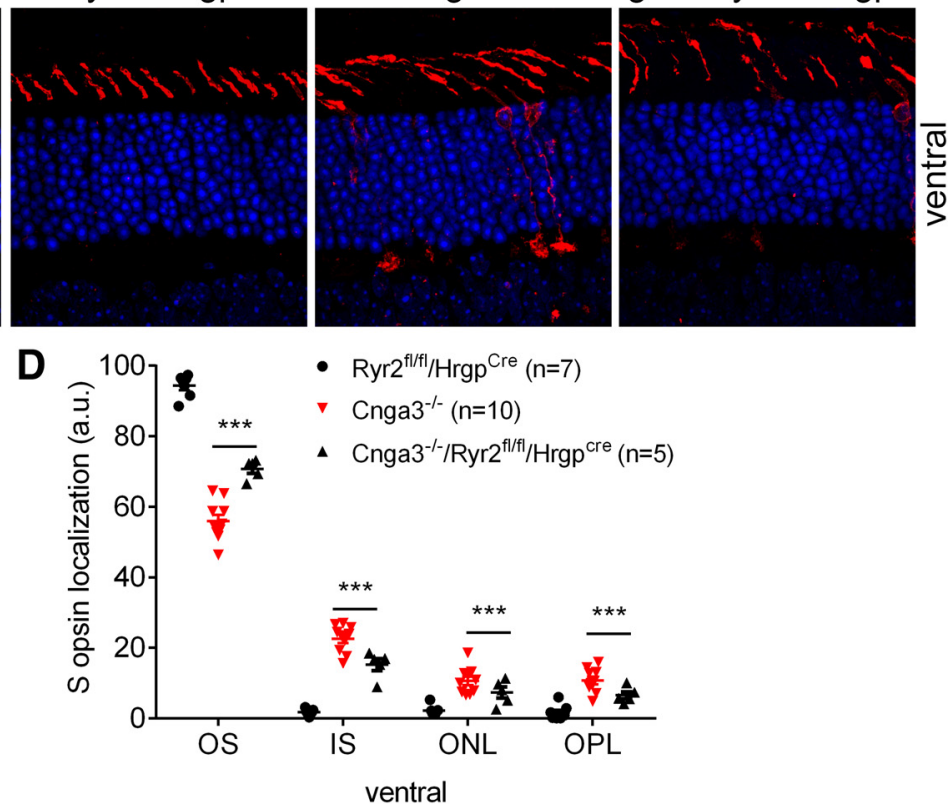

Figure 1. Deletion of Ryr2 increased OS localization of cone opsin in $\mathrm{Cnga3}^{-/-}$mice. Cone opsin localization was evaluated by

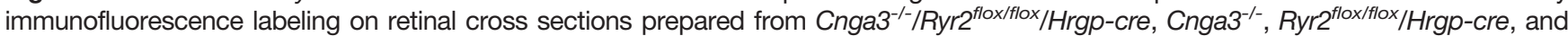
wild-type (WT) mice at P30. $\boldsymbol{A}, \boldsymbol{B}$, Representative confocal images of immunofluorescence labeling of M-opsin (A), and corresponding quantitative analysis of immunofluorescence intensity level at different regions of the retinal cross sections $(\boldsymbol{B})$. $\boldsymbol{C}, \boldsymbol{D}$, Representative confocal images of immunofluorescence labeling of $\mathbf{S}$-opsin on ventral retina $(\boldsymbol{C})$ and corresponding quantitative analysis of immunofluorescence intensity level at different regions of the retinal cross sections $(\boldsymbol{D})$. Data are presented as mean \pm SEM. $* p<0.05, * * p<0.01, * * * p<0.001$. 

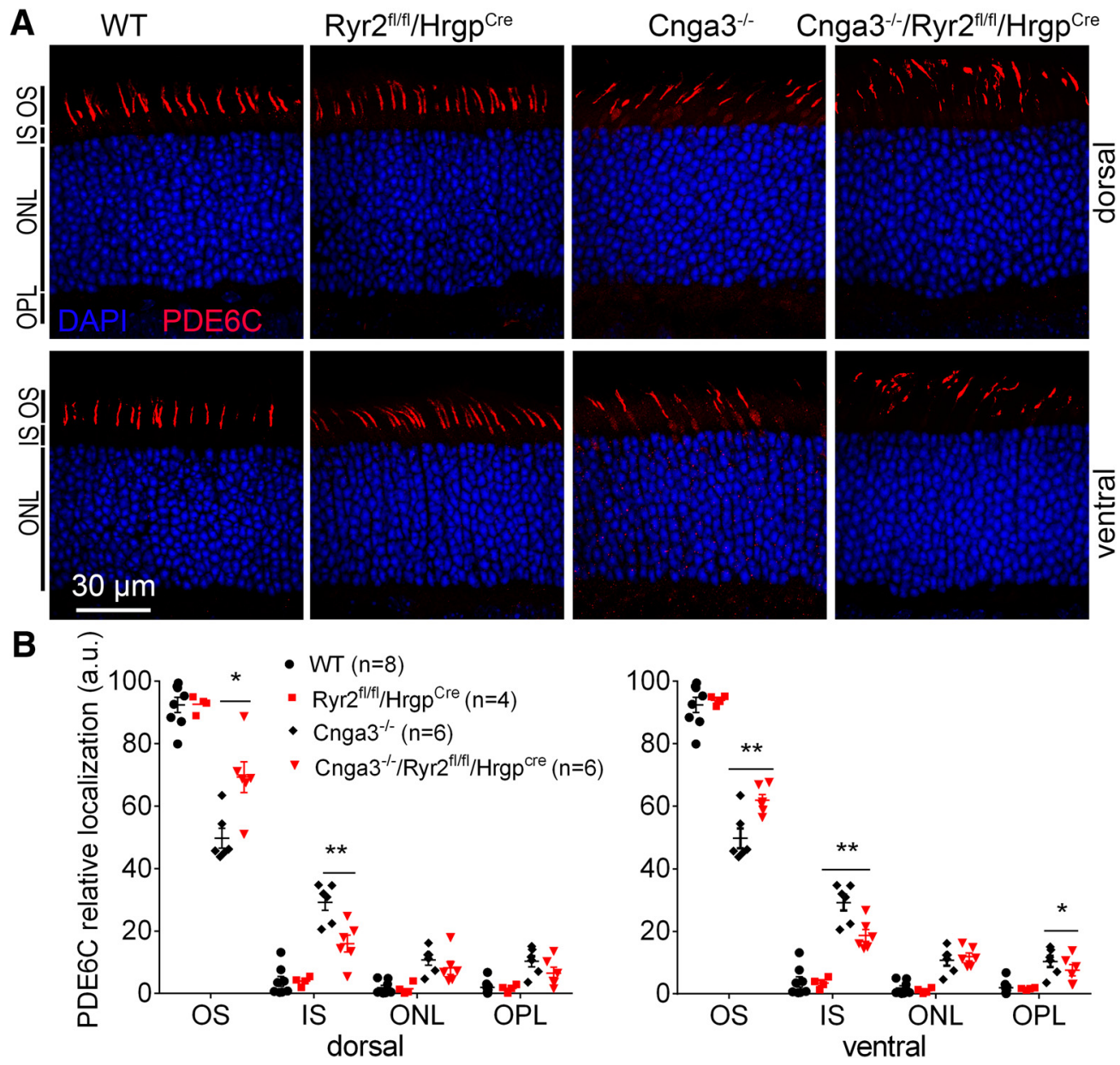

Figure 2. Deletion of Ryr2 increased OS localization of PDE6C in $\mathrm{Cnga3}^{-/-}$mice. PDE6C localization was evaluated by immunoflu-

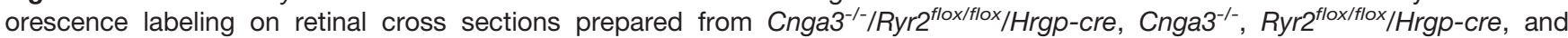
wild-type (WT) mice at P30. Shown are representative confocal images of immunofluorescence labeling of PDE6C (A) and corresponding quantitative analysis of immunofluorescence intensity level at different regions of the retinal cross sections $(\boldsymbol{B})$. Data are presented as mean \pm SEM. $* p<0.05, * * p<0.01$.

\section{Deletion of Ryr2 improved cone survival in $\mathrm{Cnga3}^{-/-}$mice}

CNG channel-deficient mice display early onset, progressive cone degeneration with more severe degeneration in the ventral retina (Michalakis et al., 2005; Xu et al., 2011). We examined whether deletion of Ryr2 improves cone survival. Cnga3 ${ }^{-1-}$ /

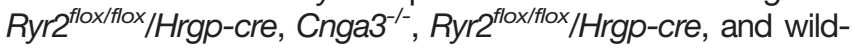
type mice at 4 months of age were examined for cone density by peanut agglutinin (PNA) labeling on retinal whole mounts and retinal cross sections. The data from this evaluation are presented in Figure 3. Deletion of Ryr2 significantly increased cone density in $\mathrm{Cnga3}^{-/-}$mice. Evaluations on retinal whole mounts showed that the number of PNA-positive cells in the ventral and dorsal retina was increased by $\sim 28$ and $17 \%$,


with age-matched $\mathrm{Cnga3}^{-/-}$controls (Fig. 3A). There was no difference in the number of PNA-labeled cones between Ryr2 $^{\text {flox/flox}} / \mathrm{Hrgp}$-cre and wild-type mice (Fig. $3 A$ ). Similar results were obtained from evaluations on retinal cross sections, showing cone density was increased by $\sim 26 \%$ in $\mathrm{Cnga3}^{-/ /} /$Ryr2 $^{\text {flox/flox }} / \mathrm{Hrgp}$-cre mice compared with $\mathrm{Cnga3}^{-/-}$ controls (Fig $3 B$ ). In a separate experiment, we examined cone density in mice at 2 months and obtained similar findings. The number of PNA-positive cells in the ventral and dorsal retina was increased by $\sim 28$ and $13 \%$, respectively, in $\mathrm{Cnga3}^{-/-} / \mathrm{Ryr}^{\text {flox/flox}} / \mathrm{Hrgp}$-cre mice compared with agematched $\mathrm{Cnga3}^{-/}$controls (Fig. $3 C$ ).

To determine whether deletion of Ryr2 in cones affects photoreceptor function, we performed ERG analysis in

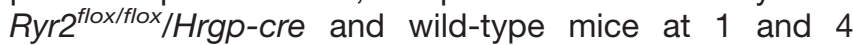
months. The evaluations showed that the $a$ - and b-waves of the scotopic and photopic responses were not different between Ryr2 $2^{\text {flox/flox} / H r g p-c r e ~ a n d ~ w i l d-t y p e ~ m i c e ~(F i g . ~ 4), ~}$ indicating that deletion of Ryr2 in cones did not affect photoreceptor function. Cnga3 $^{-/-}$mice at 1 month displayed normal scotopic responses but no photopic responses (data not shown), as reported previously (Biel et al., 1999).

\section{Deletion of Ryr2 reduced ER stress and cone apoptosis in CNG channel-deficient mice}

Cone death in CNG channel-deficient mice involves ER stress-associated apoptosis (Thapa et al., 2012; Ma et al., 2013, 2015). Retinas of CNG channel-deficient mice display ER stress, characterized by the activation of the 

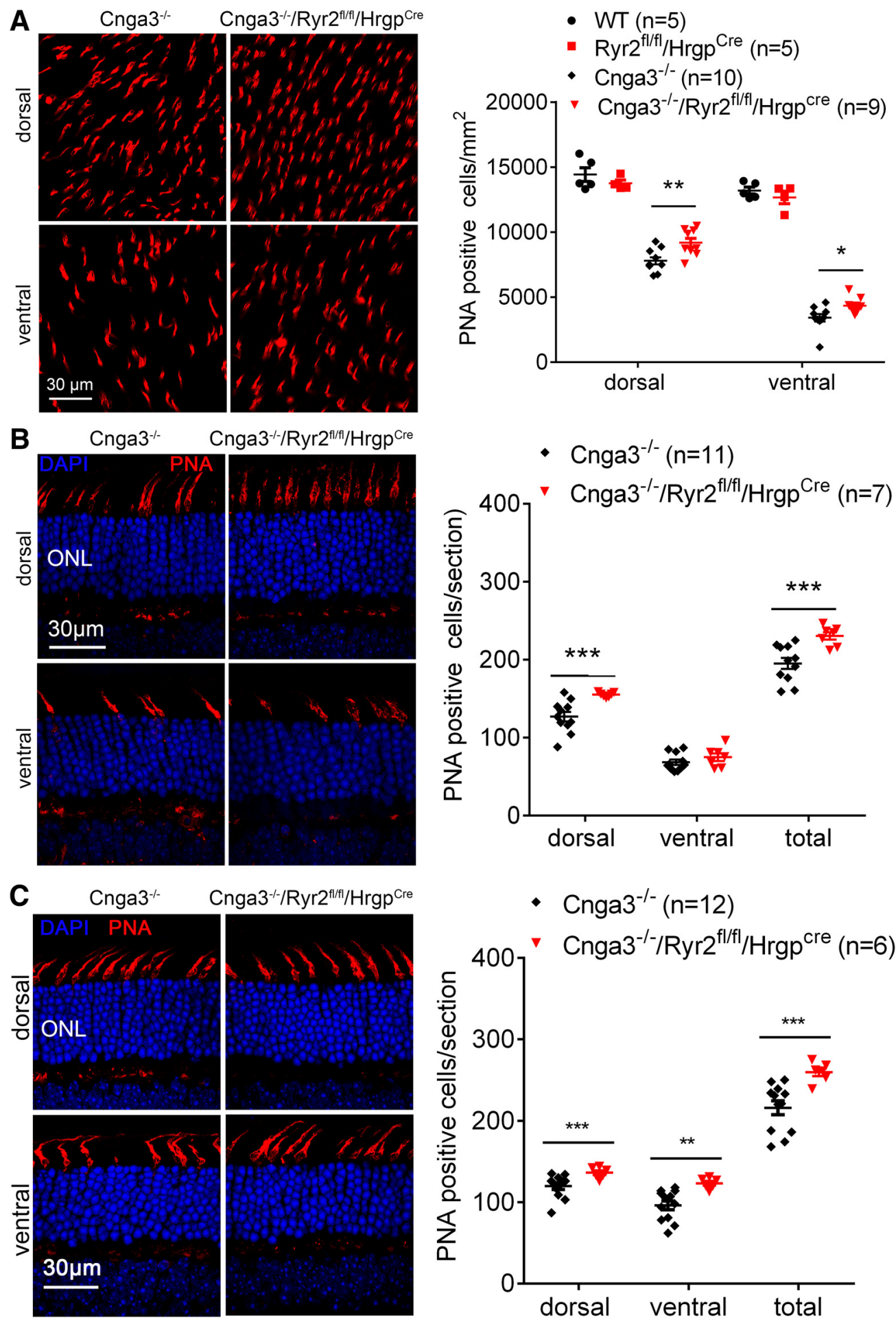

Figure 3. Deletion of Ryr2 improved cone survival in $\mathrm{Cnga}^{-/-}$mice. Cone density was evaluated by PNA immunofluorescence labeling

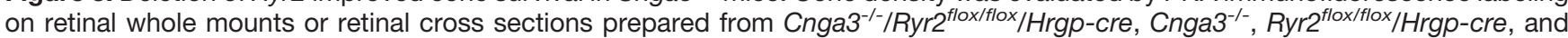
wild-type (WT) mice. Shown are representative confocal images of PNA labeling on retinal whole mounts $(\boldsymbol{A})$ and retinal cross sections (B) prepared from mice at 4 months, and PNA labeling on retinal cross sections prepared from mice at 2 months $(\boldsymbol{C})$, and corresponding quantitative analysis. Data are presented as mean \pm SEM. $* p<0.05, * * p<0.01, * * * p<0.001$.

eukaryotic initiation factor $2 \alpha(\mathrm{elF} 2 \alpha)$ and activation of the serine/threonine-protein kinase/endoribonuclease $1 \alpha$ (IRE1 $\alpha$; Thapa et al., 2012; Ma et al., 2015). This work examined effects of Ryr2 deletion on the ER stress and cone apoptosis. Cnga3 ${ }^{-/-} / \mathrm{Ryr}^{\mathrm{flox} / \mathrm{flox}} / \mathrm{Hrgp}-\mathrm{Cre}_{\mathrm{Nr}} \mathrm{Nr}^{-1-}$ (CR2N) line with deficiency of Cnga3 and Ryr2 on a cone (or cone-like)-dominant retina background $\left(\mathrm{Nr}^{-1-}\right.$ background) was generated to evaluate ER stress in cones. 
A

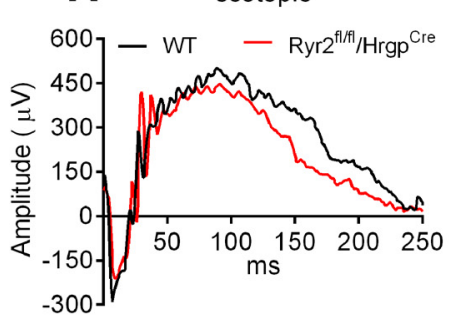

B

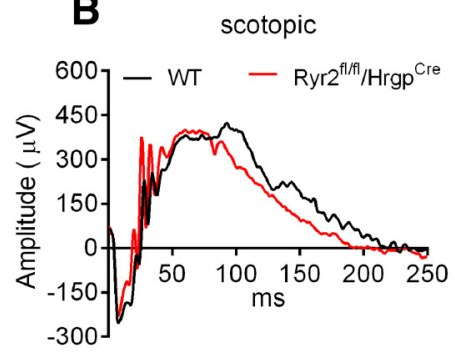

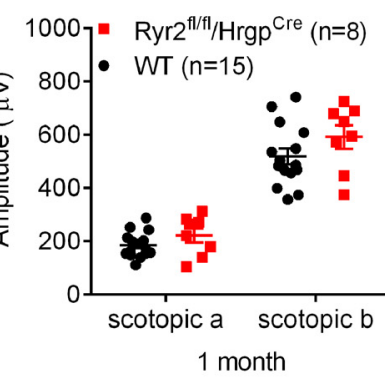

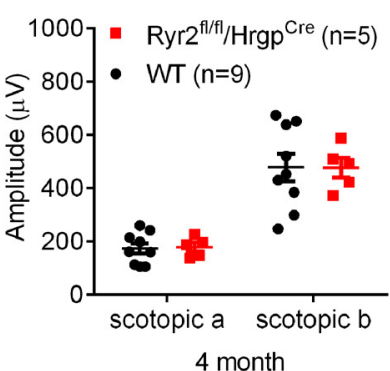

photopic

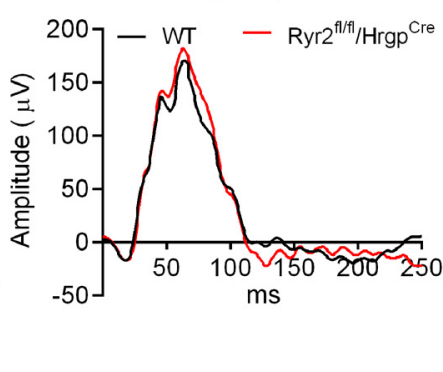

photopic

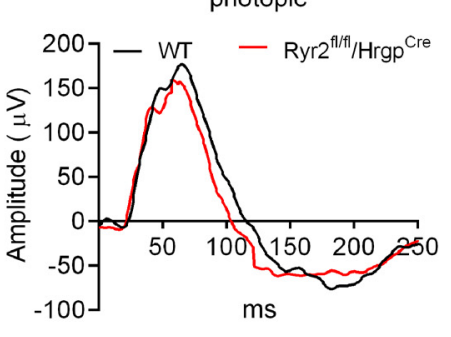



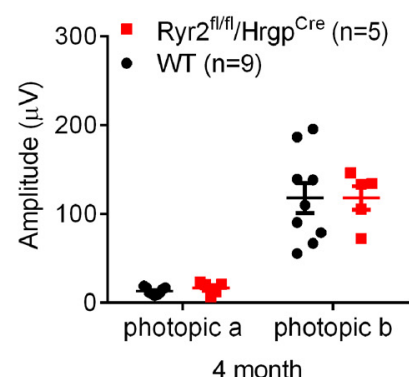

Figure 4. Deletion of Ryr2 did not affect retinal light responses in wild-type mice. Retinal light responses in Ryr flox/flox/Hrgp-cre and wild-type (WT) mice were evaluated by ERG analysis. Shown are representative scotopic and photopic ERG recording waves and quantification of the ERG recordings in Ryr2 flox/flox/Hrgp-cre and WT mice at $1(\boldsymbol{A})$ and 4 months $(\boldsymbol{B})$. Data are presented as mean \pm SEM.

Mice lacking NRL, a rod-specific neural retina leucine zipper transcription factor, confer a cone-dominant retina (Mears et al., 2001). We have previously shown that $\mathrm{Cnga}^{-1 /} / \mathrm{Nr}^{-1-}$ mice display loss of cone function and cone degeneration similar to $\mathrm{Cnga3}^{-/-}$mice (Thapa et al., 2012; Ma et al., 2013, 2015). Retinas of CR2N, Cnga3--$/ \mathrm{Nrl}^{-1-}$, and $\mathrm{Nr}^{-1-}$ mice at P15 and P30 were evaluated for levels of ER stress markers. We found that deletion of Ryr2 significantly reduced ER stress. The elevated levels of phospho-IRE $1 \alpha$ and phospho-elF $2 \alpha$ were nearly completely reversed in CR2N retinas compared with agematched $\mathrm{Cnga3}^{-1-} / \mathrm{Nrl}^{-1-}$ retinas (Fig. 5).

Effects of Ryr2 deletion on cone apoptosis were evaluated by TUNEL. We found that Ryr2 deletion significantly reduced cone death in $\mathrm{Cnga3}^{-/-}$and $\mathrm{Cnga3}^{-/-} / \mathrm{Nrl}^{-1-}$ mice. The number of TUNEL-positive cells in $\mathrm{Cnga3}^{-/ /} /$Ryr $^{\text {flox/flox/ }}$ Hrgp-cre mice at P15 was reduced by $\sim 46 \%$ compared with that in $\mathrm{Cnga3}^{-/-}$mice (Fig. 6A). Similar results were obtained in CR2N mice. The number of TUNEL-positive cells in CR2N mice was reduced by $\sim 52 \%$ compared with that in $\mathrm{Cnga3}^{-/-} / \mathrm{Nr}^{-/-}$mice (Fig. 6B).

\section{Deletion of Ryr2 in cones reduced activation of Müller cells in $\mathrm{Cnga3}^{-/-}$mice}

Müller glia are known to activate in response to retinal stress, including photoreceptor degeneration, by profound upregulation of glial fibrillary acidic protein (GFAP) in intermediate filaments. GFAP expression was previously shown to be increased in CNG channel-deficient retinas (Michalakis et al., 2005; Ma et al., 2015). In this study, we examined GFAP expression in $\mathrm{Cnga3}^{-/-}$mice with Ryr2 deletion. $\mathrm{Cnga3}^{-/ /} / \mathrm{Rry}^{\text {flox/flox}} / \mathrm{Hrgp}-\mathrm{Cre}, \mathrm{Cnga3}^{-/-}$, Ryr2 $2^{\text {flox/flox } / \mathrm{Hrgp}-}$ cre, and wild-type mice at P30 were evaluated for expression of GFAP by immunolabeling on retinal sections. We found that deletion of Ryr2 significantly reduced expression of GFAP in $\mathrm{Cnga3}^{-/-}$mice. The retinal sections from $\mathrm{Cnga3}^{-/-}$


Figure 5. Deletion of Ryr2 reduced ER stress in retinas of $\mathrm{Cnga3}^{-/-} / \mathrm{Nr}^{-/-}$mice. Expression levels of ER stress marker proteins phospho-IRE1 $\alpha$ and phospho-elF2 $\alpha$ in retinas of $\mathrm{Cnga3}^{-/-} / \mathrm{Ryr}^{\mathrm{flox} / \mathrm{flox}} / \mathrm{Hrgp}-\mathrm{Cre}^{-\mathrm{Nr}^{-/-}}$(CR2N), $\mathrm{Cnga3}^{-/-} / \mathrm{Nrl}^{-/-}$, and $\mathrm{Nrl}^{-/-} \mathrm{mice}$ at P15 and P30 were analyzed by Western blot analysis. Shown are representative Western blot images of these detections and corresponding quantitative analysis, following normalization to internal loading control $\beta$-actin. Data are presented as mean \pm SEM of three independent assays using retinas from 6 to 8 mice. $* p<0.05$. 


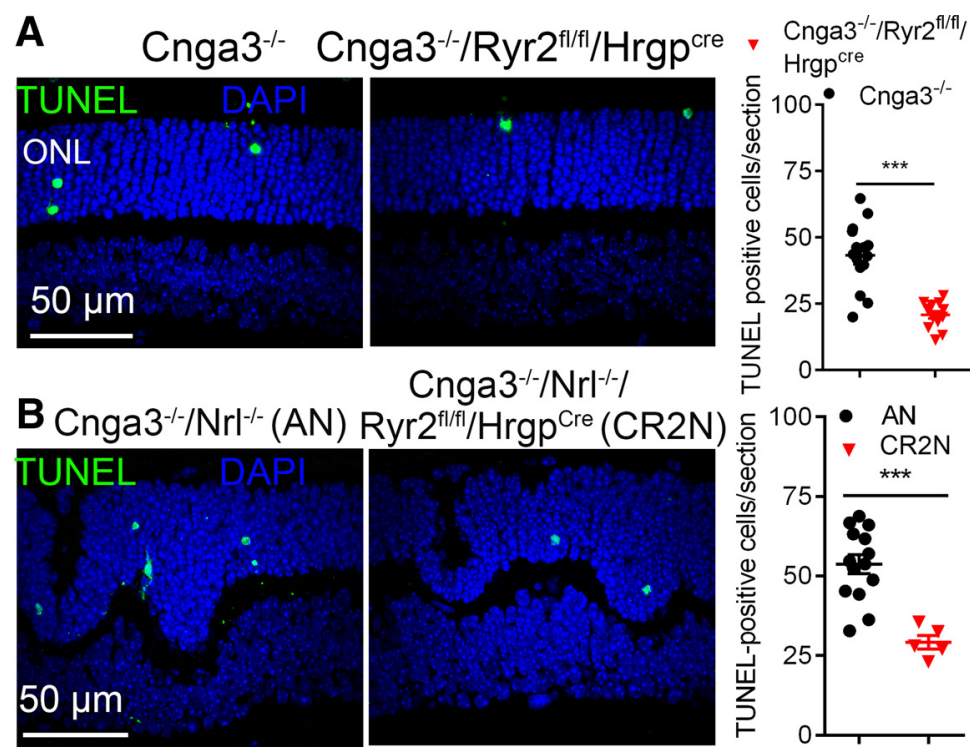

Figure 6. Deletion of Ryr2 reduced cone apoptosis in $\mathrm{Cnga3}^{-/-}$and $\mathrm{Cnga3}^{-/-} / \mathrm{Nr}^{-/-}$mice. Photoreceptor apoptosis was evaluated by TUNEL labeling on retinal cross sections of CNG channel-deficient mice at P15. Shown are representative confocal images of TUNEL labeling and correlating quantitative analysis in $\mathrm{Cnga}^{-/-} / \mathrm{Ryr}^{\text {flox/flox }} / \mathrm{Hrgp}$-cre and $\mathrm{Cnga3}^{-/-}$mice, and corresponding quantitative

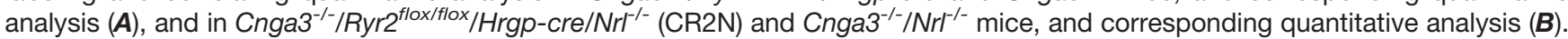
Data are represented as mean \pm SEM. $* * * p<0.001$.

mice showed significant upregulation of GFAP, with immunostaining mainly detected in the inner plexiform layers and the ganglion cell layer (Fig. 7), and this elevation was completely reversed by deletion of Ryr2 with expression levels of GFAP comparable to those in Ryr2 flox/flox $/ \mathrm{Hrgp}$-cre mice (Fig. 7). The GFAP labeling in Ryr2 $2^{f l o x / f l o x} / \mathrm{Hrgp}$-cre mice was not different from that in wild-type mice (data not shown).

\section{Discussion}

Cones in $\mathrm{Cnga3}^{-/-}$mice display characteristics of protein mislocalization, ER stress-associated apoptosis, and cellular/ER calcium dysregulation/deficiency. As a $\mathrm{Ca}^{2+}$ store, the ER is the site of protein folding/processing, and ER calcium homeostasis is crucial for protein folding and subsequent trafficking (Duncan et al., 2010; Mekahli et al.,

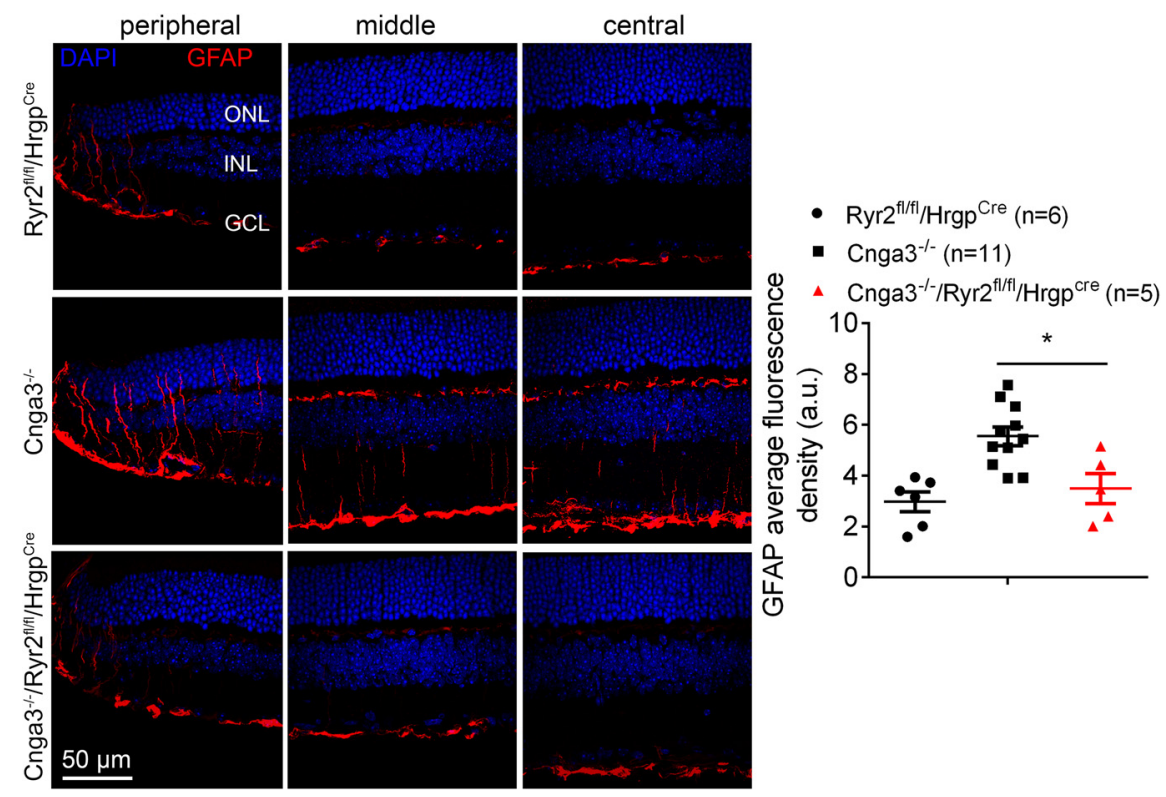

Figure 7. Deletion of Ryr2 reduced activation of Müller glial cells in $\mathrm{Cnga3}^{-/-}$mice. GFAP immunofluorescence labeling was performed

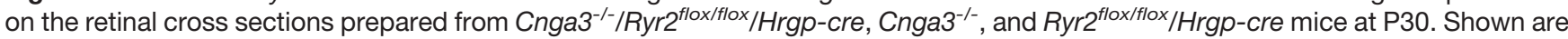
representative confocal images of immunofluorescence labeling of GFAP on the peripheral, middle, and central regions of the retinal sections and corresponding quantification of immunofluorescence intensity. RGC, Retinal ganglion cell. Data are presented as mean \pm SEM. $* p<0.05$. 
2011). We hypothesized a role of ER $\mathrm{Ca}^{2+}$ deficiency in protein mislocalization in photoreceptor degeneration and investigated the effects of Ryr2 deletion. We show that OS localization of cone opsins and PDE6C was significantly increased in $\mathrm{Cnga3}^{-/} / \mathrm{Ryr}^{\text {flox/flox}} / \mathrm{Hrgp}$-cre mice compared with $\mathrm{Cnga3}^{-/-}$mice, IS localization of these proteins were significantly decreased, and the localization improvement was accompanied with reduced ER stress, improved cone survival, and reduced retinal stress/remodeling. Our findings demonstrate a role of RyR2/ER calcium dysregulation in protein mislocalization, ER stress and cone death in CNG channel deficiency. Deletion of Ryr2 did not affect cone function, survival, and protein localization in wild-type mice, suggesting that healthy cones are not sensitive to lack of RyR2 (at least at the ages examined). It should be mentioning that deletion of Ryr2 did not cause compensatory elevation of expression of IP3R or other isoforms of RyR (Bround et al., 2012).

\section{Deletion of Ryr2 is sufficient to improve OS localization of cone proteins}

Although all three isoforms of RyR are expressed in mouse retinas RyR2 is the predominant form expressed (Shoshan-Barmatz et al., 2007; Butler et al., 2017). Deletion of Ryr2 improved protein OS localization, suggesting that targeting RyR2 is sufficient to improve ER calcium homeostasis and protein processing. It should be pointed out that deletion of Ryr2 leads to only partial rescue of protein OS localization, suggesting an incomplete correction of $\mathrm{ER} \mathrm{Ca}^{2+}$ deficiency. There are several possible explanations. First, as shown previously, ER calcium dysregulation in $\mathrm{Cnga3}^{-/-}$mice is also contributed by IP3R activity (Butler et al., 2017). The elevated IP3R function (in response to reduced cytosolic $\mathrm{Ca}^{2+}$ and elevated cGMP/ PKG signaling) continues dysregulating ER calcium homeostasis in $\mathrm{Cnga}^{-/-}$mice with Ryr2 deletion. Second, there are other ER calcium/protein folding regulators, including ER shaping proteins (Zhang and Hu, 2016; Agrawal et al., 2017) and chaperones (Hartl et al., 2011; Saibil, 2013). These factors might have been involved in the impaired protein processing in CNG channel deficiency. Third, there are other $\mathrm{Ca}^{2+}$ channels in the IS membranes, including stromal interaction molecule proteins and transient receptor potential channels (Baldridge et al., 1998; Szikra et al., 2008). These channels might have been involved in the cytosolic/ER calcium dysregulation in CNG channel deficiency. Moreover, although $\mathrm{Cnga3}^{-/-}$cones experience ER calcium dysregulation, this may not be the only problem that these cells experience. For instance, CNG channel deficiency results in malformation of cone OS (Biel et al., 1999; Ding et al., 2009). This could also be a possible reason for incomplete rescue in protein localization.

\section{RyR2 function/ER calcium dysregulation represents a potential mechanism of protein mislocalization in photoreceptors}

Photoreceptors are highly polarized neurons with cilia structure. Proper trafficking and location to the OS of the signaling and structural proteins is essential for photoreceptor functioning. Protein mislocalization is commonly observed in animal models of photoreceptor degenerative diseases. There are two well known mechanisms. One is because of the defects of the trafficking machinery, such as the ciliary protein centrosomal protein of $290 \mathrm{kDa}$ (CEP290), retinitis pigmentosa GTPase regulator (Rachel et al., 2012a,b), and Arf-like protein 3 (Hanke-Gogokhia et al., 2016). The other is related to the mutations of photoreceptor proteins that interfere with folding of the proteins, such as S334ter and $\mathrm{P} 23 \mathrm{H}$ rhodopsin mutants (Concepcion and Chen, 2010; Gorbatyuk et al., 2010; Griciuc et al., 2010). This work showing improved protein OS localization after deletion of Ryr2 demonstrates the contribution of RyR2 function/ER calcium dysregulation to protein mislocalization. The precise mechanism underlying how deletion of RyR2/inhibition of $\mathrm{ER} \mathrm{Ca}^{2+}$ release improves protein localization remains to be elucidated. It is our general assumption/hypothesis that deletion of RyR2/inhibition of ER $\mathrm{Ca}^{2+}$ release may not affect protein trafficking directly. Instead, it likely improves ER protein processing/folding function, which is highly regulated by $\mathrm{ER} \mathrm{Ca}^{2+}$ level and might be impaired in CNG channeldeficient mice; the improved protein processing in turn facilitates protein localization. The potentially impaired protein processing/ER protein homeostasis in CNG channel-deficient cones is supported by the following observations. (1) Treatment with the chemical chaperone tauroursodeoxycholic acid (Ma et al., 2013; Butler et al., 2017) and molecular chaperone 11-cis-retinal (our unpublished observations) reduced ER stress and cone apoptosis, and (2) CNG channel-deficient cones showed increased cleavage of the activating transcription factor 6 and increased phosphorylation of IRE1 $\alpha$ (Ma et al., 2015; Butler et al., 2017), which reflect unfolded protein response (UPR) and increased ER-associated protein degradation (Hetz, 2012; Wang and Kaufman, 2012). Nevertheless, the effects of CNG channel deficiency on $\mathrm{ER} \mathrm{Ca}{ }^{2+}$ level and ER protein processing/folding function, and the consequences after deletion of $\mathrm{ER} \mathrm{Ca}^{2+}$ channels merit further investigation.

\section{Deletion of Ryr2 is sufficient to reduce ER stress/ cone apoptosis and improve cone survival}

Though protein localization was partially improved in


were nearly completely corrected in these mice and cone apoptosis was greatly reduced. These data suggest that targeting RyR2 is sufficient to correct ER stress and reduce cone apoptosis. ER calcium dysregulation and its contribution to ER stress/cone death in CNG channeldeficient mice has been supported by several findings. These mice show the elevated expression/activity of RyR2 and treatment with chemical inhibitors of RyR reduces ER stress and cone apoptosis (Butler et al., 2017). These mice also show elevated expression/activity of IP3R, and treatment with chemical inhibitors of IP3R reduces ER stress/ cone apoptosis and increases cone opsin OS localization (Butler et al., 2017). Moreover, the ER stress-associated cone apoptotic death has been well documented in CNG channel-deficient mice. Retinas of these mice show elevation of all three arms of the ER stress pathways, i.e., elevated 


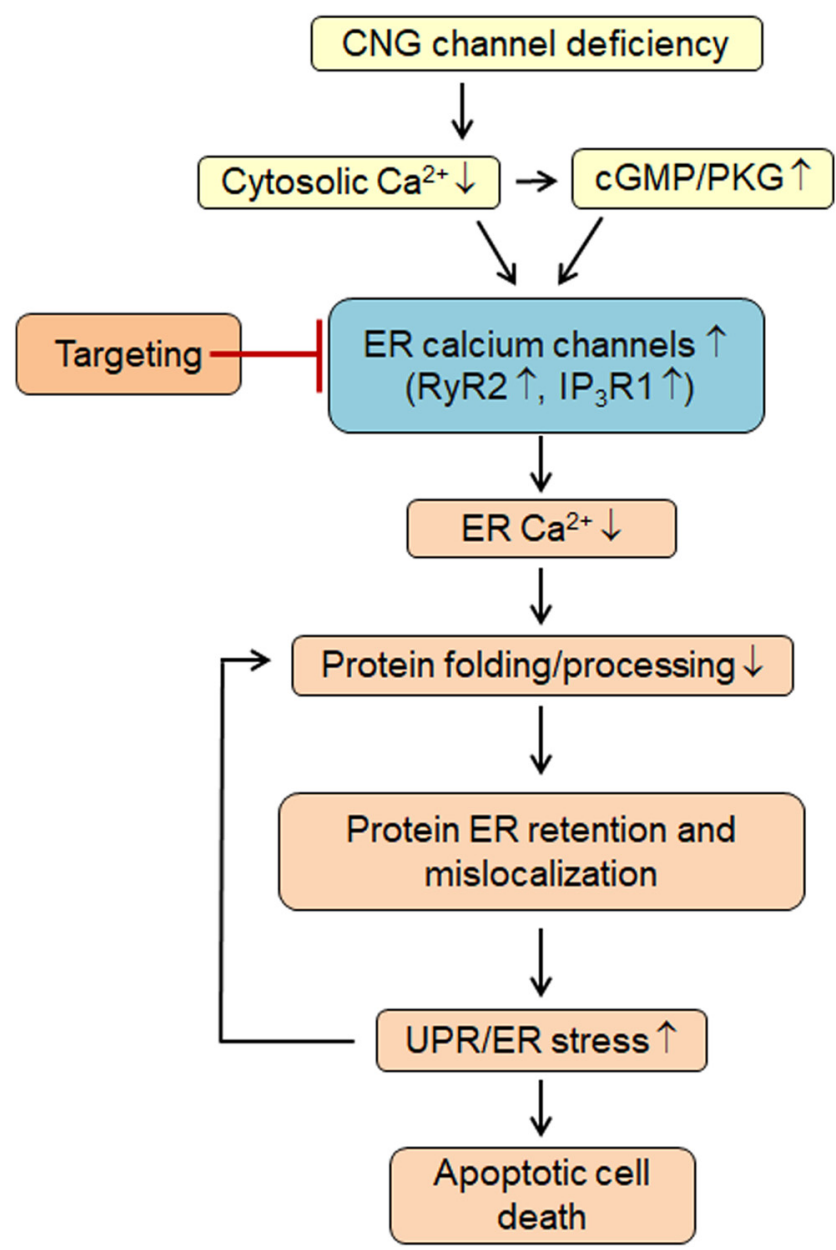

Figure 8. Potential mechanisms of protein mislocalization, ER stress, and cone death in CNG channel deficiency: involvement of ER calcium dysregulation. In $\mathrm{Cnga3}^{-/-}$cones, cytosolic $\mathrm{Ca}^{2+}$ is reduced, which increases cellular cGMP level and PKG signaling. Decreased cytosolic $\mathrm{Ca}^{2+}$ and increased cGMP/PKG signaling activates $\mathrm{ER} \mathrm{Ca}^{2+}$ channels to remedy the cytosolic $\mathrm{Ca}^{2+}$ perturbation. As a consequence, the ER experiences calcium dysregulation/deficiency, which interferes with protein processing/folding and leads to protein ER retention and impaired localization. Furthermore, UPR/ER stress likely in turn further interferes with ER protein processing. Suppression of $\mathrm{ER} \mathrm{Ca}^{2+}$ release by targeting $\mathrm{ER} \mathrm{Ca}^{2+}$ channels retains $\mathrm{Ca}^{2+}$ in the ER, maintains the ER calcium homeostasis and protein processing/folding function, improves protein localization, and reduces ER stress/cone death.

levels of phospho-elF $2 \alpha$ and phospho-IRE $1 \alpha$ and increased cleavage of ATF6 (Thapa et al., 2012; Ma et al., 2015; Butler et al., 2017), as well as increased nuclear localization of CCAAT/-enhancer-binding protein homologous protein (Thapa et al., 2012; Ma et al., 2015). These mice also show up-regulation of the cysteine protease calpains and cleavage of caspase-12 and caspase- 7 in the retina (Thapa et al., 2012).

Potential mechanisms of protein mislocalization, ER stress, and cone death in CNG channel deficiency: involvement of ER calcium dysregulation (Fig. 8)

As nonselective cation channels, CNG channels are the main source of the $\mathrm{Ca}^{2+}$ inward currents in the OS of photoreceptors and play a pivotal role in the light response/adaptation and cellular calcium homeostasis. Cone photoreceptors lacking functional CNG channels experience cellular calcium perturbation/cytosolic $\mathrm{Ca}^{2+}$ reduction (Butler et al., 2017) and subsequently elevated cellular cGMP/PKG signaling (Xu et al., 2013). The reduced cytosolic $\mathrm{Ca}^{2+}$ level and elevated cGMP/PKG signaling leads to excessive $\mathrm{ER} \mathrm{Ca}^{2+}$ release via activation of ER $\mathrm{Ca}^{2+}$ channels (Ma et al., 2015; Butler et al., 2017), which consequently leads to ER calcium dysregulation and interferes with protein processing/folding, resulting protein localization impairment and UPR/ER stress. Chemical or genetic targeting ER $\mathrm{Ca}^{2+}$ channels may represent a novel strategy to improve ER protein processing and relieve ER stress.

In summary, the present study shows that deletion of Ryr2 improved protein OS localization and suppressed ER stress/cone apoptosis. Moreover, deletion of Ryr2 improved cone survival and reduced retinal stress/remodeling. The findings demonstrate a role of RyR2 function/ER calcium dysregulation in protein mislocalization and cellular stress/death in CNG channel deficiency, and provide novel insights into the mechanisms of photoreceptor degeneration. Because altered calcium signaling, protein processing impairment, and ER stress-associated cell death are common throughout retinal degenerative diseases, insights into these dynamic signaling pathways would help development of strategies targeting ER calcium regulation for photoreceptor protection.

\section{References}

Agrawal SA, Burgoyne T, Eblimit A, Bellingham J, Parfitt DA, Lane A, Nichols R, Asomugha C, Hayes MJ, Munro PM, Xu M, Wang K, Futter CE, Li Y, Chen R, Cheetham ME (2017) REEP6 deficiency leads to retinal degeneration through disruption of ER homeostasis and protein trafficking. Hum Mol Genet 26:2667-2677.

Baehr W, Palczewski K (2009) Focus on molecules: guanylate cyclase-activating proteins (GCAPs). Exp Eye Res 89:2-3.

Baldridge WH, Kurennyi DE, Barnes S (1998) Calcium-sensitive calcium influx in photoreceptor inner segments. J Neurophysiol 79: 3012-3018.

Bales KL, Gross AK (2016) Aberrant protein trafficking in retinal degenerations: the initial phase of retinal remodeling. Exp Eye Res 150:71-80.

Biel M, Seeliger M, Pfeifer A, Kohler K, Gerstner A, Ludwig A, Jaissle G, Fauser S, Zrenner E, Hofmann F (1999) Selective loss of cone function in mice lacking the cyclic nucleotide-gated channel CNG3. Proc Natl Acad Sci U S A 96:7553-7557.

Bonigk W, Altenhofen W, Müller F, Dose A, Illing M, Molday RS, Kaupp UB (1993) Rod and cone photoreceptor cells express distinct genes for cGMP-gated channels. Neuron 10:865-877.

Bround MJ, Asghari P, Wambolt RB, Bohunek L, Smits C, Philit M, Kieffer TJ, Lakatta EG, Boheler KR, Moore ED, Allard MF, Johnson JD (2012) Cardiac ryanodine receptors control heart rate and rhythmicity in adult mice. Cardiovasc Res 96:372-380.

Butler MR, Ma H, Yang F, Belcher J, Le YZ, Mikoshiba K, Biel M, Michalakis S, luso A, Križaj D, Ding XQ (2017) Endoplasmic reticulum (ER) $\mathrm{Ca}(2+)$-channel activity contributes to ER stress and cone death in cyclic nucleotide-gated channel deficiency. J Biol Chem 292:11189-11205.

Carvalho LS, Xu J, Pearson RA, Smith AJ, Bainbridge JW, Morris LM, Fliesler SJ, Ding XQ, Ali RR (2011) Long-term and age-dependent restoration of visual function in a mouse model of CNGB3associated achromatopsia following gene therapy. Hum Mol Genet 20:3161-3175. 
Concepcion F, Chen J (2010) Q344ter mutation causes mislocalization of rhodopsin molecules that are catalytically active: a mouse model of Q344ter-induced retinal degeneration. PLoS One 5:e10904.

Ding XQ, Harry CS, Umino Y, Matveev AV, Fliesler SJ, Barlow RB (2009) Impaired cone function and cone degeneration resulting from CNGB3 deficiency: down-regulation of CNGA3 biosynthesis as a potential mechanism. Hum Mol Genet 18:4770-4780.

Duncan RS, Goad DL, Grillo MA, Kaja S, Payne AJ, Koulen P (2010) Control of intracellular calcium signaling as a neuroprotective strategy. Molecules 15:1168-1195.

Gorbatyuk MS, Knox T, LaVail MM, Gorbatyuk OS, Noorwez SM, Hauswirth WW, Lin JH, Muzyczka N, Lewin AS (2010) Restoration of visual function in $\mathrm{P} 23 \mathrm{H}$ rhodopsin transgenic rats by gene delivery of BiP/Grp78. Proc Natl Acad Sci U S A 107:5961-5966.

Griciuc A, Aron L, Piccoli G, Ueffing M (2010) Clearance of Rhodopsin(P23H) aggregates requires the ERAD effector VCP. Biochim Biophys Acta 1803:424-434.

Hackos DH, Korenbrot JI (1999) Divalent cation selectivity is a function of gating in native and recombinant cyclic nucleotide-gated ion channels from retinal photoreceptors. J Gen Physiol 113:799.

Hanke-Gogokhia C, Wu Z, Gerstner CD, Frederick JM, Zhang H, Baehr W (2016) Arf-like Protein 3 (ARL3) Regulates Protein Trafficking and Ciliogenesis in Mouse Photoreceptors. J Biol Chem 291:7142-7155.

Hartl FU, Bracher A, Hayer-Hartl M (2011) Molecular chaperones in protein folding and proteostasis. Nature 475:324-332.

Hetz C (2012) The unfolded protein response: controlling cell fate decisions under ER stress and beyond. Nat Rev Mol Cell Biol 13:89-102.

Huang W, Xing W, Ryskamp DA, Punzo C, Krizaj D (2011) Localization and phenotype-specific expression of ryanodine calcium release channels in C57BL6 and DBA/2J mouse strains. Exp Eye Res 93:700-709.

Kaupp UB, Seifert R (2002) Cyclic nucleotide-gated ion channels. Physiol Rev 82:769-824.

Kohl S, Marx T, Giddings I, Jägle H, Jacobson SG, Apfelstedt-Sylla E, Zrenner E, Sharpe LT, Wissinger B (1998) Total colour blindness is caused by mutations in the gene encoding the alpha-subunit of the cone photoreceptor cGMP-gated cation channel. Nat Genet 19:257-259.

Komáromy AM, Alexander JJ, Rowlan JS, Garcia MM, Chiodo VA, Kaya A, Tanaka JC, Acland GM, Hauswirth WW, Aguirre GD (2011) Gene therapy rescues cone function in congenital achromatopsia. Hum Mol Genet 19:2581-2593.

Krizaj D (2012) Calcium stores in vertebrate photoreceptors. Adv Exp Med Biol 740:873-889.

Krizaj D, Copenhagen DR (2002) Calcium regulation in photoreceptors. Front Biosci 7:d2023-2044.

Krizaj D, Lai FA, Copenhagen DR (2003) Ryanodine stores and calcium regulation in the inner segments of salamander rods and cones. J Physiol 547:761-774.

Le YZ, Ash JD, Al-Ubaidi MR, Chen Y, Ma JX, Anderson RE (2004) Targeted expression of Cre recombinase to cone photoreceptors in transgenic mice. Mol Vis 10:1011-1018.

Ma H, Butler MR, Thapa A, Belcher J, Yang F, Baehr W, Biel M, Michalakis S, Ding XQ (2015) cGMP/protein kinase g signaling suppresses inositol 1,4,5-trisphosphate receptor phosphorylation and promotes endoplasmic reticulum stress in photoreceptors of cyclic nucleotide-gated channel-deficient mice. J Biol Chem 290: 20880-20892.

Ma H, Thapa A, Morris L, Redmond TM, Baehr W, Ding XQ (2014) Suppressing thyroid hormone signaling preserves cone photoreceptors in mouse models of retinal degeneration. Proc Natl Acad Sci U S A 111:3602-3607.
Ma H, Thapa A, Morris LM, Michalakis S, Biel M, Frank MB, Bebak M, Ding XQ (2013) Loss of cone cyclic nucleotide-gated channel leads to alterations in light response modulating system and cellular stress response pathways: a gene expression profiling study. Hum Mol Genet 22:3906-3919.

Mears AJ, Kondo M, Swain PK, Takada Y, Bush RA, Saunders TL, Sieving PA, Swaroop A (2001) Nrl is required for rod photoreceptor development. Nat Genet 29:447-452.

Mekahli D, Bultynck G, Parys JB, De Smedt H, Missiaen L (2011) Endoplasmic-reticulum calcium depletion and disease. Cold Spring Harb Perspect Biol 3:a004317.

Michalakis S, Geiger H, Haverkamp S, Hofmann F, Gerstner A, Biel M (2005) Impaired opsin targeting and cone photoreceptor migration in the retina of mice lacking the cyclic nucleotide-gated channel CNGA3. Invest Ophthalmol Vis Sci 46:1516-1524.

Michalakis S, Mühlfriedel R, Tanimoto N, Krishnamoorthy V, Koch S, Fischer MD, Becirovic E, Bai L, Huber G, Beck SC, Fahl E, Büning $\mathrm{H}$, Paquet-Durand F, Zong X, Gollisch T, Biel M, Seeliger MW (2010) Restoration of cone vision in the $\mathrm{CNGA}^{-/-}$mouse model of congenital complete lack of cone photoreceptor function. Mol Ther 18:2057-2063.

Nishiguchi KM, Sandberg MA, Gorji N, Berson EL, Dryja TP (2005) Cone cGMP-gated channel mutations and clinical findings in patients with achromatopsia, macular degeneration, and other hereditary cone diseases. Hum Mutat 25:248-258.

Olshevskaya EV, Ermilov AN, Dizhoor AM (2002) Factors that affect regulation of cGMP synthesis in vertebrate photoreceptors and their genetic link to human retinal degeneration. Mol Cell Biochem 230:139-147.

Rachel RA, Li T, Swaroop A (2012a) Photoreceptor sensory cilia and ciliopathies: focus on CEP290, RPGR and their interacting proteins. Cilia 1:22.

Rachel RA, May-Simera HL, Veleri S, Gotoh N, Choi BY, MurgaZamalloa C, Mclntyre JC, Marek J, Lopez I, Hackett AN, Zhang J, Brooks M, den Hollander Al, Beales PL, Li T, Jacobson SG, Sood R, Martens JR, Liu P, Friedman TB, et al. (2012b) Combining Cep290 and Mkks ciliopathy alleles in mice rescues sensory defects and restores ciliogenesis. J Clin Invest 122:1233-1245.

Saibil H (2013) Chaperone machines for protein folding, unfolding and disaggregation. Nat Rev Mol Cell Biol 14:630-642.

Shoshan-Barmatz V, Zakar M, Shmuelivich F, Nahon E, Vardi N (2007) Retina expresses a novel variant of the ryanodine receptor. Eur J Neurosci 26:3113-3125.

Szikra T, Cusato K, Thoreson WB, Barabas P, Bartoletti TM, Krizaj D (2008) Depletion of calcium stores regulates calcium influx and signal transmission in rod photoreceptors. J Physiol 586:48594875.

Thapa A, Morris L, Xu J, Ma H, Michalakis S, Biel M, Ding XQ (2012) Endoplasmic reticulum stress-associated cone photoreceptor degeneration in cyclic nucleotide-gated channel deficiency. J Biol Chem 287:18018-18029.

Wang S, Kaufman RJ (2012) The impact of the unfolded protein response on human disease. J Cell Biol 197:857-867.

Xu J, Morris L, Fliesler SJ, Sherry DM, Ding XQ (2011) Early-onset, slow progression of cone photoreceptor dysfunction and degeneration in CNG channel subunit CNGB3 deficiency. Invest Ophthalmol Vis Sci 52:3557-3566.

Xu J, Morris L, Thapa A, Ma H, Michalakis S, Biel M, Baehr W, Peshenko IV, Dizhoor AM, Ding XQ (2013) cGMP accumulation causes photoreceptor degeneration in CNG channel deficiency: evidence of cGMP cytotoxicity independently of enhanced CNG channel function. J Neurosci 33:14939-14948.

Zhang H, Hu J (2016) Shaping the Endoplasmic Reticulum into a Social Network. Trends Cell Biol 26:934-943. 